\title{
Contagem celular somática: relação com a composição centesimal do leite e período do ano no Estado de Goiás
}

\author{
Somatic cell count: relationship to milk composition and period of the \\ year in Goiás State, Brazil
}

\author{
Válter Ferreira Félix Bueno ${ }^{1}$ Albenones José de Mesquita ${ }^{2}$ Edmar Soares Nicolau ${ }^{2}$ \\ Antônio Nonato de Oliveira ${ }^{2}$ Jaison Pereira de Oliveira ${ }^{2}$ Rodrigo Balduíno Soares Neves ${ }^{3}$ \\ José Ricardo Garcia Mansur ${ }^{3}$ Liandra Werner Thomaz ${ }^{4}$
}

\section{RESUMO}

Apesar de estar entre os maiores produtores de leite do país, o Estado de Goiás não tem estudos abrangentes $e$ atualizados relativos à qualidade do leite. Objetivou-se com o presente estudo avaliar a relação existente entre a contagem celular somática (CCS) e os teores de gordura, proteína, lactose e sólidos totais do leite cru armazenado em tanques de refrigeração por expansão direta de uso individual, no Estado de Goiás, além de verificar a influência do período do ano sobre a CCS. Os dados utilizados pertencem ao arquivo de resultados do Laboratório de Qualidade do Leite do Centro de Pesquisa em Alimentos da Escola de Veterinária da Universidade Federal de Goiás. Foram tabulados os dados da CCS e composição centesimal referentes ao período de outubro de 2002 a setembro de 2003. A CCS foi determinada através de citometria de fluxo e a composição centesimal através da absorção diferencial de ondas infravermelhas. Foram considerados dois períodos distintos no ano: período das chuvas, de novembro a abril, e período das secas, de maio a outubro. A concentração de proteína, lactose e sólidos totais foi inversamente correlacionada com a CCS. A temperatura ambiente apresentou correlação positiva e significativa com o escore de células somáticas, sendo que as maiores médias da CCS ocorreram no período das secas.

Palavras-chave: células somáticas, Goiás, mastite, qualidade do leite.

\section{ABSTRACT}

Milk quality is a crescent concern in Brazil and the Goiás State does not have any current studies on this subject, although it is among the major producers in the country. The aim of this survey was to verify the relationship between somatic cell count (SCC) and milk composition (fat, protein, lactose and total solids content) and the influence of year period in SCC in Goiás State, Brazil. Data were obtained from October 2002, to September 2003 in the Laboratory of Milk Quality of the Center of Food Research in the Veterinary School of the Federal University of Goiás. SCC was analyzed through flow citometry and milk composition by infrared differential absorption. The year period was divided in two seasons: a rainy season, from November to April, and a dry season, from May to October. Protein, lactose and total solids content decreased as SCC elevated. Environmental temperature showed positive and significant correlation to score of somatic cells, and the highest averages of SCC occurred in the dry season.

Key words: Goiás, mastitis, milk quality, somatic cell.

\section{INTRODUÇÃO}

A contagem celular somática (CCS) tem sido considerada, medida padrão de qualidade, pois está relacionada com a composição, rendimento industrial e segurança alimentar do leite. Para os produtores, possui alta relevância, porque indica o estado sanitário das glândulas mamárias das vacas, podendo sinalizar para perdas significativas de produção e alterações da qualidade do leite (HARMON, 1994; SANTOS, 2001).

${ }^{1}$ Escola de Veterinária (EV), Universidade Federal de Goiás (UFG), Centro de Pesquisa em Alimentos, Campus II da UFG, rodovia GO-080 (saída para Nova Veneza), 74001-970, Goiânia, GO, Brasil. E-mail: vbueno@ vet.ufg.br. Autor para correspondência. ${ }^{2}$ Centro de Pesquisa em Alimentos (CPA), EV, UFG, Goiânia, GO, Brasil.

${ }^{3}$ Laboratório de Qualidade do Leite, CPA, EV, UFG, Goiânia, GO, Brasil.

${ }^{4} \mathrm{EV}$, UFG, Goiânia, GO, Brasil. 
Em virtude da ação de lipases leucocitárias e lipoprotéicas, a concentração de gordura no leite com elevada CCS tende a diminuir (HARMON, 1994; AULDIST et al., 1995; BRITO \& DIAS, 1998). No entanto, PEREIRA et al. (1999) encontraram maior concentração de gordura no leite de vacas com mastite. MACHADO et al (2000) observaram que a partir de 1.000 .000 cels $\mathrm{mL}^{-1}$ ocorria significativo aumento na concentração desse componente, em amostras colhidas em tanques de expansão.

A caseína do leite sofre expressiva redução quando a CCS aumenta, devido à ação de proteases leucocitárias e sanguíneas. Por outro lado, ao mesmo tempo ocorre aumento das proteínas plasmáticas no leite em decorrência da resposta inflamatória. Dessa forma, a percentagem de proteína total no leite com elevada CCS reduz apenas $1 \%$, em relação à concentração encontrada no leite de vacas sem mastite (HARMON, 1994).

Resultados de trabalhos realizados no Brasil enfocando a relação entre a quantidade de células somáticas e a concentração de proteína no leite são contraditórios. PEREIRA et al. (1999) observaram que o teor de proteína era maior em amostras de leite com CCS acima de 283.000cels $\mathrm{mL}^{-1}$, enquanto MACHADO et al. (2000) verificaram que a partir de 500.000cels $\mathrm{mL}^{-1}$ ocorria redução no teor protéico.

Segundo HARMON (1994), a redução da concentração de lactose no leite com alta CCS equivale a $10 \%$ do valor normal. BRITO \& DIAS (1998) mencionaram que a intensidade da redução varia de $5 \%$ a $20 \%$. MACHADO et al. (2000) observaram redução significativa na concentração de lactose em amostras colhidas em tanques de expansão com CCS acima de 500.000cels $\mathrm{mL}^{-1}$. SILVAet al. (2000) verificaram redução no teor de lactose de $4,68 \%$ para $4,49 \%$, considerando amostras de leite de vacas com CCS abaixo e acima de 283.000cels $\mathrm{mL}^{-1}$, respectivamente.

MACHADO et al. (2000) verificaram que, em amostras colhidas em tanques de expansão, com CCS abaixo de 500.000cels $\mathrm{mL}^{-1}$, o teor médio de sólidos totais correspondia a 12,37\%. BRITO \& DIAS (1998) afirmaram que a presença de mastite acarreta redução na concentração de sólidos totais em intensidade variável entre $3 \%$ e $12 \%$. MACHADO et al. (2000) e SILVA et al. (2000) não verificaram diferença significativa na concentração de sólidos totais à medida que ocorria elevação da CCS.

A infecção intramamária consiste no fator que exerce a maior influência sobre a CCS (PHILPOT \& NICKERSON, 2002). Estágio e ordem de lactação avançados relacionam-se com maior CCS, apenas quando há infecção da glândula (SHELDRAKE et al.,
1983; LAEVENS et al., 1997). Fatores estressantes, principalmente o calor, podem aumentar a CCS. No entanto, observa-se elevação relativa, decorrente da menor secreção (HARMON, 1994).

ALLORE et al. (1997) verificaram diferenças na CCS relacionadas com a estação do ano e região geográfica. PHILPOT \& NICKERSON (2002) afirmaram que a CCS pode ser maior nas estações e regiões de temperatura e umidade ambiente mais elevadas, devido à maior probabilidade de ocorrer infecção intramamária. VASCONCELOS et al. (1997) não observaram diferenças entre a CCS de amostras de leite colhidas no verão e no inverno, no Estado de São Paulo. No Paraná, OSTRENSKY (1999) verificou que os resultados da CCS eram maiores no período de novembro a abril do que entre maio e outubro. No Rio Grande do Sul, NORO et al. (2004) verificaram que o escore de células somáticas era maior no mês de maio.

Apesar do Estado de Goiás destacar-se no cenário nacional devido à sua elevada produção de leite, são poucos os dados relativos à qualidade do leite cru. Paralelamente, observa-se crescente reconhecimento da importância da qualidade do leite, tanto por empresas do setor quanto pelos órgãos de regulação e fiscalização. O Ministério da Agricultura, Pecuária e Abastecimento estabeleceu padrões e normas para a produção de leite no país, envolvendo a CCS (BRASIL, 2002). As normas estão contidas na Instrução Normativa no 51 (IN 51) e os padrões da CCS serão exigidos a partir de 01/07/2005, nas regiões Sul, Sudeste e Centro-Oeste do país, inicialmente.

Diante do exposto, objetivou-se com o presente estudo avaliar a relação existente entre a CCS e os teores de gordura, proteína, lactose e sólidos totais do leite cru armazenado em tanques de refrigeração por expansão direta de uso individual, no Estado de Goiás, além de verificar a influência do período do ano sobre a CCS.

\section{MATERIAL E MÉTODOS}

Os dados utilizados no presente trabalho pertencem ao arquivo de resultados do Laboratório de Qualidade do Leite do Centro de Pesquisa em Alimentos da Escola de Veterinária da UFG. Foram reunidos os resultados da CCS e composição centesimal (teores percentuais de gordura, proteína, lactose e sólidos totais) de amostras de leite colhidas em tanques de refrigeração por expansão direta de uso individual, no período de outubro de 2002 a setembro de 2003.

Foram utilizados os resultados de 18.949 amostras analisadas quanto à CCS e composição 
centesimal. A CCS foi realizada através de citometria de fluxo, utilizando o equipamento Fossomatic 5000 Basic e a composição centesimal determinada através da absorção diferencial de ondas infravermelhas, utilizando o equipamento Milkoscan 4000.

Para avaliar a influência do período do ano sobre a CCS, foram considerados dois períodos distintos no ano: período das chuvas e das secas, sendo o período das chuvas equivalente aos meses de novembro a abril, e o das secas aos meses de maio a outubro. ACCS foi transformada em escore linear de células somáticas $\left(\mathrm{ECS}=\left[\log _{2}(\mathrm{CCS} / 100.000)\right]+3\right)$, de acordo com DABDOUTB \& SHOOK (1984) para realização das análises estatísticas.

Os dados meteorológicos foram obtidos junto à Empresa Brasileira de Pesquisa Agropecuária Centro Nacional de Pesquisa em Arroz e Feijão (Embrapa-CNPAF), na estação Capivara, localizada em Santo Antônio de Goiás, distante $12 \mathrm{~km}$ de Goiânia. Foram consideradas as médias mensais máximas de temperatura e umidade relativa do ar e a precipitação pluviométrica mensal total.

Fez-se a comparação de médias através do teste $t$ de Student, análise de variância e determinação do coeficiente de correlação linear (r). O nível de confiança considerado foi de $95 \%$. Para avaliar a influência da CCS, variável independente, sobre os teores de gordura, proteína, lactose e sólidos totais, variáveis dependentes, calculou-se o coeficiente de correlação linear (r) entre cada variável independente e as respectivas variáveis dependentes.

Para realização da análise de variância, foram considerados cinco intervalos da CCS, estabelecidos de acordo com seus valores fisiológicos e regulatórios (BRASIL, 2002; PHILPOT \& NICKERSON, 2002): resultados menores ou iguais a 200.000cels mL $\mathrm{mL}^{-1}$ (1), de 201.000 a 400.000cels $\mathrm{mL}^{-1}$ (2), de 401.000 a 750.000 cels $\mathrm{mL}^{-1}$ (3), de 751.000 a 1.000.000cels $\mathrm{mL}^{-1}$ (4) e acima de 1.000 .000 cels $\mathrm{mL}^{-1}(5)$. Calculou-se também o coeficiente de correlação linear entre as temperaturas e as médias mensais do ECS, entre as umidades relativas do ar e as médias mensais do ECS e entre a precipitação pluviométrica total e as médias mensais do ECS.

\section{RESULTADOS E DISCUSSÃO}

Os percentuais médios de gordura, proteína, lactose e sólidos totais do leite, de acordo com o intervalo da CCS, bem como a variação observada em cada componente, considerando a diferença entre o intervalo 1 (CCS menor ou igual a $200.000 \mathrm{cels}_{\mathrm{mL}}^{-1}$ ) e o 5 (CCS acima de 1.000.000cels $\mathrm{mL}^{-1}$ encontram-se na tabela 1. Pode-se observar na tabela 1 que ocorreu redução significativa nos teores de proteína, lactose e sólidos totais com o aumento da CCS. Em relação ao teor de gordura, observou-se diferença significativa apenas entre os teores do intervalo 1 (CCS menor ou igual a 200.000cels $\mathrm{mL}^{-1} \mathrm{e} 2$ (CCS entre $201.000 \mathrm{e}$ 400.000cels $\mathrm{mL}^{-1}$ ).

Os coeficientes de correlação linear (r) entre o ECS e os valores percentuais de gordura, proteína, lactose e sólidos totais do leite, encontram-se na tabela 2 . Observa-se a ocorrência de correlação significativa entre o ECS e os teores de gordura, proteína, lactose e sólidos totais do leite, embora os valores possam ser considerados baixos. Constata-se também que apenas $0,16 \%$ da variação do teor de gordura deve-se ao ECS, enquanto em relação ao teor de lactose esse percentual corresponde a $17,64 \%$.

Observando os teores médios de gordura nos diferentes intervalos da CCS (tabela 1), constatase que praticamente não houve variação entre os diferentes intervalos, ao contrário de HARMON (1994), AULDIST et al. (1995) e BRITO \& DIAS (1998), que mencionaram a ocorrência de redução conforme aumento da CCS. Por outro lado, observa-se que no intervalo 2 o teor de gordura foi significativamente maior do que no intervalo 1 (Tabela 1). Embora não tenha ocorrido diferença significativa entre os demais

Tabela 1- Percentuais médios de gordura, proteína, lactose e sólidos totais do leite, de acordo com o intervalo da contagem de células somáticas (CCS) de amostras analisadas no período de outubro de 2002 a setembro de 2003, no Estado de Goiás.

\begin{tabular}{|c|c|c|c|c|}
\hline $\mathrm{CCS}(\mathrm{x} 1.000 \mathrm{CS} / \mathrm{mL})$ & Gordura $(\%)^{*}$ & Proteína $(\%)^{*}$ & Lactose $(\%)^{*}$ & Sólidos totais $(\%)^{*}$ \\
\hline$\leq 200$ & $3,71 \mathrm{a}$ & $3,35 \mathrm{a}$ & $4,60 \mathrm{a}$ & $12,61 \mathrm{a}$ \\
\hline $201-400$ & $3,75 b$ & $3,31 b$ & $4,54 b$ & $12,54 b$ \\
\hline $401-750$ & $3,72 \mathrm{ab}$ & $3,23 \mathrm{c}$ & $4,49 \mathrm{c}$ & $12,39 \mathrm{c}$ \\
\hline $751-1.000$ & $3,73 \mathrm{ab}$ & $3,18 \mathrm{~d}$ & $4,42 \mathrm{~d}$ & $12,27 \mathrm{~d}$ \\
\hline$>1.000$ & $3,72 \mathrm{ab}$ & $3,18 \mathrm{~d}$ & $4,36 \mathrm{e}$ & $12,20 \mathrm{~d}$ \\
\hline Variação** & $+0,27 \%$ & $-5,07 \%$ & $-5,22 \%$ & $-3,25 \%$ \\
\hline
\end{tabular}

* Letras diferentes na mesma coluna indicam diferença significativa $(\mathrm{P}<0,05)$.

** Considerando as médias do intervalo 1 e 5. 
Tabela 2 - Correlação linear entre o escore de células somáticas e os teores de gordura, proteína, lactose e sólidos totais de 18.849 amostras de leite produzido no Estado de Goiás.

\begin{tabular}{lcccc}
\hline Componente & Tipo de correlação & $\mathrm{r}^{1}$ & P** & $\mathrm{r}^{2 * * *}$ \\
\hline Gordura & positiva & 0,04 & $<0,0001$ & 0,0016 \\
Proteína & negativa & 0,23 & $<0,0001$ & 0,0529 \\
Lactose & negativa & 0,42 & $<0,0001$ & 0,1764 \\
Sólidos totais & negativa & 0,16 & $<0,0001$ & 0,0256 \\
\hline
\end{tabular}

* Coeficiente de correlação linear

** Probabilidade de cometer erro tipo 1.

*** Coeficiente de determinação (EBERHART et al., 1982)

intervalos, a diferença observada assemelha-se aos resultados de PEREIRA et al. (1999), que encontraram maior concentração de gordura no leite de vacas com mastite. No entanto, essa elevação pode ser apenas de caráter relativo, em virtude da redução expressiva nos demais componentes (Tabela 1).

$\mathrm{O}$ aumento na concentração de gordura observado está refletido no coeficiente de correlação linear positivo que se obteve, que apesar de baixo $(0,04)$, foi significativo (tabela 2). PEREIRA et al. (1999) também obtiveram um coeficiente de correlação baixo $(0,06)$ e significativo. No entanto essa significância pode ter sido influenciada pelo grande número de amostras analisadas (SAMPAIO, 1998). Dessa forma, ao se observar o coeficiente de determinação, constata-se que a variação do ECS responde por apenas $0,16 \%$ da variação do teor de gordura (tabela 2 ), o que pode ser considerado insignificante.

Ao mesmo tempo, constata-se a grande influência de outros fatores na concentração da gordura no leite. Entre esses, destaca-se a dieta dos rebanhos. O teor de gordura do leite decresce em conseqüência da inibição da síntese na glândula mamária ou da escassez dos precursores lipídicos. A dieta pobre em fibras e que contém gordura insaturada proporciona redução de até $30 \%$ do teor de gordura do leite, comparativamente à dieta rica em fibras e com gordura saturada (GRIINARI et al., 1998).

Os componentes protéicos não foram avaliados no presente estudo, mas pode-se verificar na tabela 1 que o teor médio de proteína total reduziu significativamente à medida que a CCS aumentou. Observa-se que, no intervalo 1 (CCS menor ou igual a 200.000cels $\mathrm{mL}^{-1}$ ), o teor de proteína foi de 3,35\%, enquanto nos intervalos 4 e 5 (de 751.000 cels $\mathrm{mL}^{-1}$ a 1.000 .000 cels $\mathrm{mL}^{-1} \mathrm{e}$ acima de 1.000 .000 cels $\mathrm{mL}^{-1}$, respectivamente) esse valor foi de $3,18 \%$.
A diferença de 0,17 unidades percentuais corresponde a uma redução na proteína bruta de 5,07\% (Tabela 1), superior à descrita por HARMON (1994). Esse percentual, considerando uma produção anual de leite no Estado de Goiás de 2,36 bilhões de litros (OLIVEIRA, 2002), representaria uma perda de aproximadamente 4.000 toneladas de proteína. Considerando que $10 \mathrm{~L}$ de leite com as características descritas no intervalo 1 (3,35\% de proteína) seriam suficientes para produzir $1 \mathrm{~kg}$ de queijo mussarela, a quantidade de proteína perdida seria suficiente para produzir aproximadamente 12.000 toneladas desse queijo.

Pode-se verificar, na tabela 2, que o coeficiente de correlação entre o ECS e a concentração de proteína foi negativo. Resultado oposto ao obtido por PEREIRA et al. (1999), que verificaram concentração de proteína de $3,34 \%$ no leite com CCS acima de 283.000cels $\mathrm{mL}^{-1} \mathrm{e} 3,26 \%$ naquele com CCS abaixo desse limite. No entanto, os resultados obtidos no presente estudo, são semelhantes aos de MACHADO et al. (2000), que verificaram menor concentração de proteína em amostras de leite com CCS acima de 500.000cels $\mathrm{mL}^{-1}$. Esses autores constataram também que entre $500.000 \mathrm{e}$ 1.000.000cels $\mathrm{mL}^{-1}$ e acima de 1.500 .000 cels $\mathrm{mL}^{-1} \mathrm{o}$ percentual de proteína foi $3,18 \%$, valor idêntico ao obtido no presente estudo nos intervalos 4 e 5 (tabela 1).

Embora a correlação entre o ECS e a concentração de proteína tenha sido significativa, apenas 5,29\% das variações causadas no teor protéico podem ser justificadas por variações no ECS (tabela 2). Se essa comparação fosse traçada considerando apenas a concentração de caseína, componente que sofre maior redução (HARMON, 1994), provavelmente o coeficiente de determinação seria maior.

Pode-se verificar na tabela 1 uma significativa redução da concentração de lactose à medida que a CCS aumentou. No intervalo 1 (CCS menor ou igual a 200.000 cels $\mathrm{mL}^{-1}$ ), a média foi $4,60 \%$, enquanto no intervalo 5 (acima de 1000.000 cels $\mathrm{mL}^{-1}$ ) a média foi $4,36 \%$. Essa diferença representa uma redução de 5,22\% e está em acordo com a redução descrita por BRITO \& DIAS (1998). MACHADO et al. (2000) e SILVA et al. (2000) também observaram redução da concentração de lactose quando a CCS aumentou.

Essa redução provavelmente deve-se à lesão tecidual e também à passagem do carboidrato do lúmen alveolar para a corrente sanguínea (HARMON, 1994; AULDIST et al., 1995). A significativa correlação observada entre o ECS e a concentração de lactose, -0,42 (Tabela 2) torna-se semelhante ao coeficiente de -0,34 obtido por SILVA et al. (2000). Essa forte correlação leva à constatação de que $17,64 \%$ das 
variações do teor de lactose foram decorrentes de variações na CCS (Tabela 2). Portanto, pode-se inferir que a lactose é o componente do leite que sofre maior redução devido à elevação da CCS.

Pode-se constatar na tabela 1 que a concentração de sólidos totais reduziu significativamente conforme a CCS aumentou. A diferença de 0,41 unidades percentuais entre o intervalo 1 e o 5, reflete as alterações observadas no teor de proteína e lactose e representa uma redução de $3,25 \%$ (Tabela 1), o que está em acordo com a redução citada por BRITO \& DIAS (1998). MACHADO et al. (2000) e SILVA et al. (2000) observaram uma tendência de redução do teor de sólidos totais à medida que a CCS aumentava, no entanto sem diferença significativa. Essa ausência de significância provavelmente decorreu do fato de que os autores verificaram, concomitantemente, aumento da concentração de gordura, o que poderia mascarar o efeito da redução dos teores de proteína e lactose sobre a concentração de sólidos totais.

Pode-se observar, também na tabela 2, que a concentração de sólidos totais apresentou correlação negativa com o escore de células somáticas, embora apenas 2,56\% da variação possa ser explicada pelo ECS. Por outro lado, SILVA et al. (2000) observaram ausência de correlação significativa entre a concentração de sólidos totais e o escore linear de células somáticas.

Esses resultados contraditórios talvez possam ser explicados, pelo menos parcialmente, pelo número de amostras utilizadas: no presente trabalho foram analisadas 18.949 amostras e SILVA et al. (2000) analisaram 1.361. De acordo com SAMPAIO (1998), o número de amostras influencia a significância do resultado. No entanto, a constatação de que apenas 2,56\% das variações no teor de sólidos totais possam ser explicadas pelas variações do ECS (Tabela 2), permite inferir que a correlação, do ponto de vista prático, pode ser considerada insignificante.

Os dados meteorológicos e as médias da CCS e ECS, no período das águas e secas, encontramse na tabela 3 . Pode-se observar que não houve diferença significativa entre as médias da temperatura máxima no período das chuvas e das secas. Em relação à umidade relativa do ar e precipitação pluviométrica, a média do período das chuvas foi significativamente maior que a do período das secas. O ECS no período das secas foi significativamente maior do que no período das chuvas.

Segundo HARMON (1994) e PHILPOT \& NICKERSON (2002), a CCS pode aumentar nos meses mais quentes do ano em decorrência da menor produção de leite e conseqüente concentração das células somáticas. Alia-se a isso a maior probabilidade de ocorrência de infecção intramamária, isoladamente, o principal fator responsável pela elevação da CCS. As maiores médias da CCS obtidas no presente trabalho ocorreram nos meses de outubro de 2002 e setembro de 2003, o que levou à ocorrência de diferença significativa na CCS dos períodos das chuvas e secas (Tabela 3).

VASCONCELOS et al. (1997) observaram que as CCS de amostras de leite colhidas de quartos mamários no inverno não foram diferentes das CCS de amostras colhidas no verão, no Estado de São Paulo. Esses autores verificaram que as temperaturas máximas das duas estações foram semelhantes, a exemplo do observado no presente estudo (Tabela 3 ).

No Estado de Goiás, os meses de setembro e outubro são os últimos antes do início do período das chuvas. Portanto, em propriedades que não providenciaram volumoso em quantidade suficiente para suprir as necessidades no período de escassez de pastagens, pode ter ocorrido comprometimento da quantidade e qualidade da dieta das vacas, o que

Tabela 3 - Dados meteorológicos e médias da contagem de células somáticas (CCS) e escore de células somáticas (ECS), de acordo com o período do ano, no intervalo de outubro de 2002 a setembro de 2003, no Estado de Goiás.

\begin{tabular}{|c|c|c|c|c|c|c|c|c|}
\hline \multirow{2}{*}{ Período } & \multicolumn{3}{|c|}{ Dados meteorológicos } & \multirow{2}{*}{$\mathrm{n}^{4}$} & \multicolumn{2}{|c|}{$\mathrm{CCS}\left(\mathrm{CS} \mathrm{mL} L^{-1}\right)$} & \multicolumn{2}{|c|}{ ECS* } \\
\hline & $\mathrm{T}^{1^{*}}$ & $\mathrm{U}^{2 *}$ & $\mathrm{P}^{3^{*}}$ & & Média $^{5}$ & $\mathrm{~s}_{6}$ & Média $^{5}$ & $\mathrm{~s}_{6}$ \\
\hline Chuvas & $29,3 a$ & $93,5 a$ & $238,7 \mathrm{a}$ & 8.740 & 342.000 & 277 & $4,45 \mathrm{a}$ & 0,94 \\
\hline Secas & $30,7 \mathrm{a}$ & $80,5 b$ & $17,4 \mathrm{~b}$ & 10.209 & 352.000 & 270 & $4,49 b$ & 0,97 \\
\hline
\end{tabular}

${ }^{1}$ Media da temperatura ambiente máxima $\left({ }^{\circ} \mathrm{C}\right)$.

${ }^{2}$ Média da umidade relativa do ar máxima (\%).

${ }^{3}$ Precipitação pluviométrica total $(\mathrm{mm})$.

${ }^{4}$ Número de amostras no período.

${ }^{5}$ Média aritmética.

${ }^{6}$ Desvio padrão.

*Letras diferentes na mesma coluna indicam diferença significativa $(\mathrm{P}<0,05)$.

Ciência Rural, v.35, n.4, jul-ago, 2005. 
segundo OSTRENSKY (1999) e NORO et al. (2004) poderia estar relacionado com elevação da CCS. Dessa forma, a restrição alimentar acarretaria redução na produção de leite e conseqüentemente, concentração das células somáticas. Essa hipótese poderia ser confirmada através da medição diária da produção individual de leite e CCS individual das vacas, acompanhadas de realização de cultura microbiana.

A ocorrência de maior CCS no leite produzido nos meses de setembro e outubro também poderia estar associada à existência de várias vacas em final de lactação, nos rebanhos analisados. Ao final da lactação a CCS aumenta (OSTRENSKY, 1999) porque há uma maior ocorrência de casos de mastite e também devido à concentração das células somáticas que ocorre em função da redução fisiológica do volume de leite produzido (HARMON, 1994; PHILPOT \& NICKERSON, 2002).

Os coeficientes de correlação linear (r) entre o ECS e a temperatura, entre o ECS e a umidade relativa do ar e entre o ECS e a precipitação pluviométrica podem ser vistos na tabela 4 . Pode-se constatar que o ECS foi significativamente influenciado pela temperatura ambiente, com $64 \%$ (coeficiente de determinação) das variações do ECS devendo-se às variações da temperatura ambiente máxima. As correlações entre a umidade relativa do ar e o ECS e entre a precipitação pluviométrica e o ECS não foram significativas.

OSTRENSKY (1999) verificou que a CCS no Estado do Paraná foi maior entre novembro e abril, ao contrário do obtido no presente estudo (tabela 3 ). No entanto, o autor ressaltou que as maiores médias de temperatura máxima foram observadas nos meses de janeiro e fevereiro, compreendidos no período em que a CCS foi maior. Essa relação entre CCS e temperatura também foi constatada no presente estudo, no qual se obteve um coeficiente de correlação linear positivo $(0,80)$ entre as duas variáveis (Tabela 4).

Não foi observada correlação significativa entre o ECS e a umidade relativa do ar e entre o ECS e a precipitação pluviométrica total (Tabela 4). Constatação semelhante foi feita por VASCONCELOS et al. (1997) ao verificarem que, apesar da umidade relativa do ar do verão e inverno no Estado de São Paulo apresentarem valores diferentes, a CCS de amostras colhidas de quartos mamários nas duas estações não diferiu. Essa ausência de correlação significativa pode ser justificada pelo fato de que a umidade relativa do ar e precipitação pluviométrica geralmente estão relacionadas com maior pressão de infecção por microrganismos ambientais, os quais estão mais relacionados com casos de mastite clínica
Tabela 4 - Coeficientes de correlação linear entre o escore de células somáticas (ECS) e a temperatura ambiente, ECS e umidade relativa do ar e ECS e precipitação pluviométrica no período de outubro de 2002 a setembro de 2003, no Estado de Goiás.

\begin{tabular}{|c|c|c|c|c|}
\hline Componente & Tipo de correlação & $r^{*}$ & $\mathrm{P}^{* *}$ & $\mathrm{r}^{2} * * *$ \\
\hline Temperatura $\left({ }^{\circ} \mathrm{C}\right)$ & positiva & 0,80 & 0,0017 & 0,64 \\
\hline Umidade (\%) & negativa & 0,34 & 0,2850 & 0,1156 \\
\hline Precipitação (mm) & negativa & 0,13 & 0,6938 & 0,0169 \\
\hline
\end{tabular}

* Coeficiente de correlação linear.

** Probabilidade de cometer erro tipo 1.

**** Coeficiente de determinação (EBERHART et al., 1982).

(FONSECA \& SANTOS, 2000). Considerando que normalmente o leite de vacas com mastite clínica é descartado, esses casos não influenciam a CCS do tanque de expansão.

\section{CONCLUSÕES}

Diante dos resultados obtidos e de acordo com as condições de realização do presente estudo, pode-se concluir que a elevação da contagem de células somáticas está relacionada à redução das concentrações de proteína, lactose e sólidos totais e que, no Estado de Goiás, o leite apresenta contagem de células somáticas mais elevada no período das secas.

\section{AGRADECIMENTOS}

Ao $\mathrm{CNPq}$, pela bolsa de mestrado do primeiro autor, à equipe do CPA, pelo apoio irrestrito e à EmbrapaCNPAF, pela cessão dos dados meteorológicos.

\section{FONTE DE AQUISIÇÃO}

Fossomatic 5000 Basic e Milkoscan 4000: Foss Electric A/S. Hilleröd, Denmark.

\section{REFERÊNCIAS}

ALLORE, G.H. et al. Effects of season, herd size, and geographic region on the composition and quality of milk in the Northeast. Journal of Dairy Science, Champaign, v.80, n.11, p.3040-3049, 1997.

AULDIST, M. J. et al. Changes in the compositional of milk from healthy and mastitic dairy cows during the lactation cycle. Australian Journal of Experimental Agriculture, Melbourne, v.35, n.4, p.427-436, 1995.

BRASIL. Instrução Normativa n. 51 de 18 de setembro de 2002. Dispõe sobre regulamentos técnicos aplicados ao leite cru e pasteurizado. Diário Oficial da União, Brasília, 20 set. 2002. Seção 1, n.183, p.13-22.

Ciência Rural, v.35, n.4, jul-ago, 2005. 
BRITO, J.R.F.; DIAS, J.C. A qualidade do leite. Juiz de Fora : Embrapa/Tortuga, 1998. 98p.

EBERHART, R.J. et al. Relationships of bulk tank somatic cell counts to prevalence of intramammary infection and to indices of herd production. Journal of Food Protection, Des Moines, v.45, n.12, p.1125-1128, 1982.

DABDOUTB, S.A.M.; SHOOK, G.E. Phenotypic relations among milk yield, somatic cell count, and clinical mastitis. Journal of Dairy Science, Champaign, v.67, n.1, p.163164, 1984. (Supplement 1).

FONSECA, L.F.L.; SANTOS, M.V. Qualidade do leite e controle de mastite. São Paulo : Lemos, 2000. 175p.

HARMON, R.J. Physiology of mastitis and factors affecting somatic cell counts. Journal of Dairy Science, Champaign, v.77, n.7, p.2103-2112, 1994.

GRIINARI, J.M. et al. Trans-octadecenoic acids and milk fat depression in lactating dairy cows. Journal of Dairy Science, Champaign, v.81, n.5, p.1251-1261, 1998.

LAEVENS, H. et al. Influence of parity and stage of lactation on the somatic cell count in bacteriologically negative dairy cows. Journal of Dairy Science, Champaign, v.80, n.12, p.3219-3226, 1997.

MACHADO, P.F. et al. Composição do leite de tanques de rebanhos brasileiros distribuídos segundo sua contagem de células somáticas. Revista Brasileira de Zootecnia, Viçosa, v.29, n.6, p.1883-1886, 2000.

NORO, G. et al. Fatores ambientais que afetam a composição do leite em rebanhos assistidos por cooperativas na região Noroeste do Rio Grande do Sul: 1. células somáticas. In: DÜRR, J.W. et al. O compromisso com a qualidade do leite no Brasil. Passo Fundo : Universitária, 2004. p.141-145.
OLIVEIRA, C. Leite: preço baixo é problema. O Popular, Goiânia, 19 jan, p.6-7, 2002. Suplemento do Campo.

OSTRENSKY, A. Efeitos de ambiente sobre a contagem de células somáticas no leite de vacas da raça holandesa no Paraná. 1999. 114f. Dissertação (Mestrado em Ciências Veterinárias) - Setor de Ciências Agrárias, Universidade Federal do Paraná.

PEREIRA, A.R. et al. Efeito do nível de células somáticas sobre os constituintes do leite I - gordura e proteína. Brazilian Journal Veterinary Research and Animal Science, São Paulo, v.36, n.3, p.429-433, 1999.

PHILPOT, N.W.; NICKERSON, S.C. Vencendo a luta contra a mastite. Piracicaba : Westfalia Surge/Westfalia Landtechnik do Brasil, 2002. 192p.

SAMPAIO, I.B.M. Estatística aplicada à experimentação animal. Belo Horizonte : Fundação de ensino e pesquisa em medicina veterinária e zootecnia, 1998. 221p.

SANTOS, M.V. Contagem de células somáticas e qualidade do leite e derivados. In: SIMPÓSIO INTERNACIONAL SOBRE PRODUÇÃO INTENSIVA DE LEITE, 5., 2001, Belo Horizonte. Anais... São Paulo : Instituto Fernando Costa, 2001. p.115-127.

SHELDRAKE, R.F. et al. Lactation stage, parity, and infection affecting somatic cells, electrical conductivity, and serum albumin in milk. Journal of Dairy Science, Champaign, v.66, n.3, p.542-547, 1983

SILVA, L.F.P. et al. Efeito do nível de células somáticas sobre os constituintes do leite II - lactose e sólidos totais. Brazilian Journal Veterinary Research and Animal Science, São Paulo, v.37, n.4, p.330-333, 2000.

VASCONCELOS, C.G.C. et al. Influência da estação do ano, do estádio de lactação e da hora da ordenha sobre o número de células somáticas do leite bovino. Arquivo Brasileiro de Medicina Veterinária e Zootecnia, Belo Horizonte, v.49, n.4. p.483-491, 1997. 